\title{
Introducing interprofessional education, practice and research in a higher education setting
}

Engaging across professions in teaching and practice facilitates improved abilities by students to address the health needs of society. ${ }^{[1]}$ Universities worldwide have therefore integrated learning outcomes and teaching activities related to interprofessional education (IPE) into their curricula. ${ }^{[2,3]}$ To this end, the Faculty of Community and Health Sciences (FCHS) at the University of the Western Cape has introduced a scaffolded approach, where IPE and collaborative practice (CP) learning activities are presented in the curriculum, as well as co-curricular activities, from first to final year. In addition to the curricular considerations, the Faculty has presented a number of development activities to ensure that academics are equipped with the knowledge and skills to act as facilitators in IPE and CP student activities. ${ }^{[4]}$ A successful grant from the National Research Foundation facilitated the implementation of an interdisciplinary community-engaged research project, which explored the needs of a rural community. In this AJHPE supplement on IPE and interprofessional practice and research we share the experiences of both academics and students, with IPE and CP interventions implemented in the FCHS. The experiences of applying a community-based participatory research approach are also presented in this supplement. Thus, a holistic approach to scholarship is presented that integrates teaching, research and community engagement.

Julie et al. ${ }^{[5]}$ explored academics' knowledge and experiences with IPE and CP. While it became clear that academics were knowledgeable of the concepts related to IPE and CP, they recommended the use of a framework to facilitate further understanding of the process. It became evident that the use of frameworks is beneficial, assisting students to identify community needs and thus plan collaborative projects to address these needs, as highlighted in the short report by Rhoda et al. ${ }^{[6]}$ Although the students supported the use of frameworks, they requested earlier exposure to them before entering the clinical setting. ${ }^{[7]}$

Senior students from the various departments in the FCHS engage in a co-curricular interprofessional learning activity on campus, namely a world café teaching strategy, to facilitate development of IPE competencies. In the exploration of the students' views on world cafés, Filies et al. ${ }^{[8]}$ found they facilitated students' knowledge about the roles of the different professionals as well as what working in interprofessional teams entails. The students who attended the world cafés also mentioned that the use of authentic learning activities would assist in the development of the skills needed to function in the clinical setting. The IPE activities, which were provided across departments in the FCHS, focused on facilitating the development of core competencies among students. Manilall and Rowe ${ }^{[9]}$ report on the development of collaboration as a competency as part of the physiotherapy curriculum. These authors found that although lecturers and students had a good understanding of collaboration, there were gaps in the curriculum in both classroom and clinical setting activities related to this concept.

In addition to engaging in interprofessional teaching and learning activities, FCHS academics also engaged in interprofessional research. Using the principles of community-based participatory research, it was evident that clear aims and implementation strategies are important considerations when implementing this type of research, as reported by Frantz et al. ${ }^{[10]}$ Capacity development of both community members and academics also emerged from this study as an important consideration. Therefore, it is evident that strategies exist that higher education institutions can use to drive the implementation of IPE and interprofessional practice and research, as functioning collaboratively in interprofessional teams is beneficial. Findings from our studies will be used to further inform IPE and interprofessional research activities in the FCHS. We hope that the findings generate further discussion on this topic and contribute to additional innovations in this field.

\section{Anthea Rhoda}

Guest Editor

Department of Physiotherapy, Faculty of Community and Health Sciences, University of the Western Cape, Cape Town, South Africa arhoda@uwc.ac.za

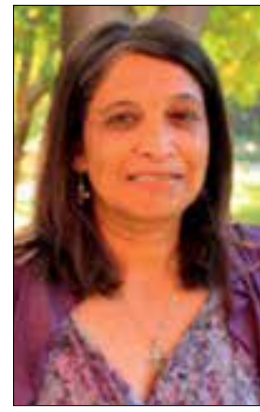

Interprofessional Education Collaborative. Connecting health professionals for better life. Core competencies for interprofessiont collaborative practice 2016 - update. http.//wwwa con nche edu/education-resources/ (accessed September 2016).

2. Snyman S, von Pressentin K, Clarke M. International Classification of Functioning, Disability and Health: Catalyst for interprofessional education and collaborative practice. J Interprof Care 2015;29(4):313. DOI:10.31 09/13561820.2015.1004041

3. Bondevick B, Haugaland M. Interprofessional workplace learning in primary care: Students from different health professions work in teams in real-life settings. Int J Teach Learn Higher Educ 2015;27(2):175-182.

4. Mclean M, Cilliers F, van Wyk J. Faculty development: Yesterday, today and tomorrow. Med Teach 2008;30:555584. DOI:10.1080/01421590802109834

5. Julie H, Hess-April L, Wilkenson J, Cassiem W, Rhoda A. Academics' knowledge and experiences of interprofessional education and practice. Afr J Health Professions Educ 2016;8(2 Suppl 2):222-224. DOI:10.7196 AJHPE.2016.v8i2.845

6. Rhoda A, Waggie F, Filies GC, Frantz JM. Using operative models (ICF and CBR) within an interprofessiona context to address community needs: A short report. Afr J Health Professions Educ 2016;8(2 Suppl 2):214-216. DOI:10.7196/AJHPE.2016.v8i2.850

7. Rhoda A, Laattoe N, Smithdorf G, Roman N, Frantz J. Facilitating community-based interprofessional education and collaborative practice in a health sciences faculty: Student perceptions and experiences. Afr J Health Professions Educ 2016:8(2 Suppl 2):225-228. DOI:10.7196/AJPPE 2016.v832 846

8. Filies G, Yasse Z Frat J.S Sto 9. Manilall J, Rowe M. Collaborative competency in physiotherapy students: Implications for interprofess education. Afr J Health Professions Educ 2016;8(2 Suppl 2):217-221. DOI:10.7196/AJHPE.2016.v8i2.841

10. Frantz J, Filies G, Jooste K, et al. Reflection on an interprofessional community-based participatory research project. Afr J Health Professions Educ 2016;8(2 Suppl 2):234-237. DOI:10.7196/AJHPE.2016.v8i2.851

Afr J Health Professions Educ 2016;8(2 Suppl 2):213. DOI:10.7196/AJHPE.2016.v8i2.861 